\title{
CABLE-STAYED CANTILEVER STRUCTURES AS AN EXPAT OF UNIQUE APPLICATION IN THE CONSTRUCTION OF A BUILDING LOCATED IN SEISMIC AREA - AN AUTHOR'S PROJECT OF MULTIFUNCTIONAL BUILDING IN LISBON, PORTUGAL
}

\author{
K. GRĘBOWSKI* and M. WERDON \\ Department of Structural Mechanics \\ Faculty of Civil and Environmental Engineering \\ Department of Technical Bases of Architectural Design \\ Faculty of Architecture, Gdansk University of Technology \\ ul. Narutowicza 11/12, 80-233 Gdansk, POLAND \\ E-mails: karol.grebowski@pg.gda.pl; malgosia.werdon@gmail.com
}

\begin{abstract}
The article presents numerical simulations for the modelling of seismic impact on the structure of unique cantilever cablestayed structure with the application of two methods. The Response Spectrum method, in which a spectrum of the structure's responses to an earthquake's impact is generated, and the Accelerogram method, in which we generate dynamic load in the form of a diagram of the connection between acceleration and time for the actual readings during a real earthquake. Both methods have been presented for the El Centro earthquake spectrum. This unique application of a cantilever cablestayed structure in public buildings will allow to assess the safety of this kind of load-bearing system in areas of increased risk of seismic activity. Cantilever cablestayed structures have so far never been designed or analyzed on seismically active areas. Based on numerical simulation we determined the effect of stiffness of load-bearing lines on the increase of stresses and displacements at cable stays joint with the end of the cantilever part of a building.
\end{abstract}

Key words: cantilever structures, seismic and dynamic analysis, cable-stayed structures.

\section{Introduction}

Nowadays modern architecture brings more and more challenges to building engineering. Traditional shapes and solutions defer to astonishing, extraordinary forms that require new alternative structure systems. Both designers and users look for unusual spaces which not only comply with the preset functions but also express the natural human need for breaking the boundaries. As a result, engineers constantly seek novel remedies or attempt to adopt existing methods to new utilisation.

Among many, we can recall for example the residential building 'HL23' in New York with its dual lateral support system and a steel plate shell wall or the Beijing National Aquatic Centre, called Water Cube made of ETFE bubbles and based on the Weaire-Phelan structure.

Another example of such exertion is an appliance of cable-stayed system not in the usual bridge structure but in a raising of a public multifunctional building. Although this solution is not yet widely known, there are few existing models already. One of them is the Cosmopolitan skyscraper, inaugurated in December 2013 in Warsaw, Poland. This 160 meters high tower serves mainly as a residential object, however, its first floors are arranged for a commercial, service and office use while its underground part has been designed to accommodate a 300-vehicle car park (Balendra, 1993; Harries and Gong, 2000).

\footnotetext{
* To whom correspondence should be addressed
} 

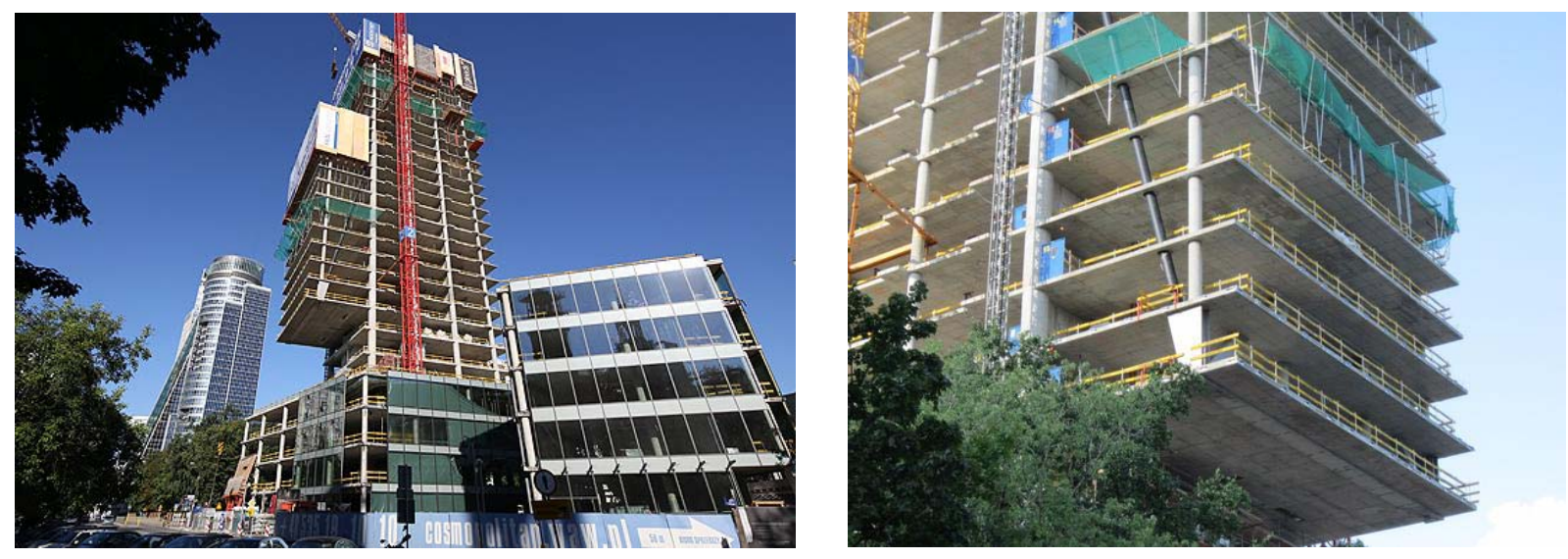

Fig.1 The unique cantilever cablestayed structure (Cosmopolitan Tower in Warsaw).

The biggest structural challenge was generated by the cantilever of the length of almost 12 meters. It begins in the eighth floor and ends in the very top of the 44-store building. To permit such an extraordinary overhang, a special structure suspended to the core of the tower has been implemented. The constructors decided to use 3 pairs of bridge cable stays inclined at an angle of $76^{\circ}$, which made it possible to suspend 11 stores by each one. The 35 meters long hangers were formed of high resistance (1860 MPa) steel lines. The first and the second pairs are made of 75 lines, while the third and the highest one is made of 109 lines. The cables are protected by conduits which, after the final adjustment, were injected with grout that ensured a proper fire protection. On levels $+8,+19$ and +30 of the cantilever steel trusses are located. Each of them is two store high and weights about 44 tones. There are passive anchors installed in lower nodes of the truss, whereas the active anchors lie in the steel retaining block which is placed inside the reinforced concrete column. To achieve proper stiffness of hangers a special design of straining process had to be made. This deign included all the stages of construction process such as building of particular stores, installation of façade, finishing works. When all the loads were present, the hangers were rectified.

All those treatments let the construction be safe and stable, proving again that in the world of structure there are no impossible things, but there are only more complicated cases (Li et al., 2003; Wu and Li, 2003).

\section{Author's project of a multifunctional building in Lisbon (Portugal)}

A similar solution was used in the author's own project of a multifunctional building in Lisbon, Portugal. Located in the very tourist zone of the capital, it was aimed to be a hub for local population providing distinctive but basic functions. Those mean public marketplace, kinder-garten, student residence, media library, robotic parking and eventually an urban garden on the rooftop. Both, the mixture of functions and the soil that due to the Great Lisbon Earthquake in the end of $18^{\text {th }}$ century, is considered to be seismically dangerous, complicate the process of structural design. Additionally, considering the architectural necessities, the form of the building requires a cantilever of almost 7 meters. General characteristics are: height 23.00 meters, width 26.25 meters, length 53.35 meters, underground floors: none, above ground floors: 6, length of cantilever: 10 meters, height of cantilever: 4 floors. Type of structure: mixed - column and slab structure with monolith core of reinforced concrete combined with post tension tendons in the floor slabs accompanied by stay cables (Englekirk, 2003). 


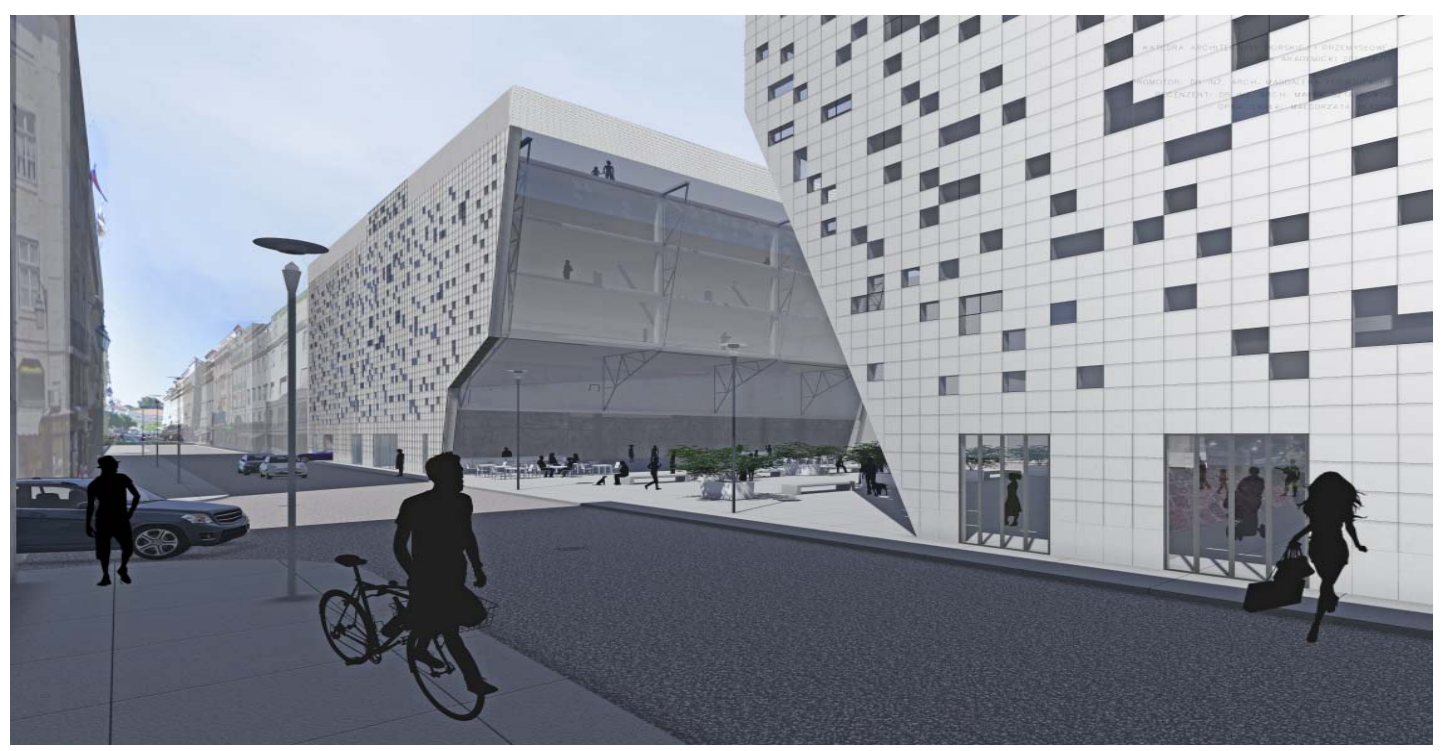

Fig.2. Visualization author's project of the building in Lisbon.

The elements of the structural system are: - reinforced concrete columns - their cross-sections are adapted to transfer all the tensions produced in the structure; - floor slabs - two directional slabs in technology of post tension tendons without adhesion: monolith concrete slabs reinforced and stressed by steel cables in situ. The singular ties that are forming part of the cable are covered by grease and led in the HDPE pipes. This solution decreases friction loses along the tie. The passive and active anchors are located in the end of cables. The ties are overpassing the active anchors outside the edge of slab to allow the tension, right after the poured concrete achieves proper resistance. In order to lighten the structure there are Cobiax synthetic void formers inserted to the slabs; - stay cables - working as hangers, formed of steel tangles and anchored actively and passively in steel retaining blocks that are located in columns of reinforced concrete; load-bearing walls - they form the core of the building, located on the opposite side of the building than the cantilever. Beside stiffening the structure their function is to provide fire evacuation; - monolith slabs of reinforced concrete - other elements of the core, work in one direction and provide fire evacuation (Harries and Gong, 2000; Kapela and Sieczkowski, 2003).
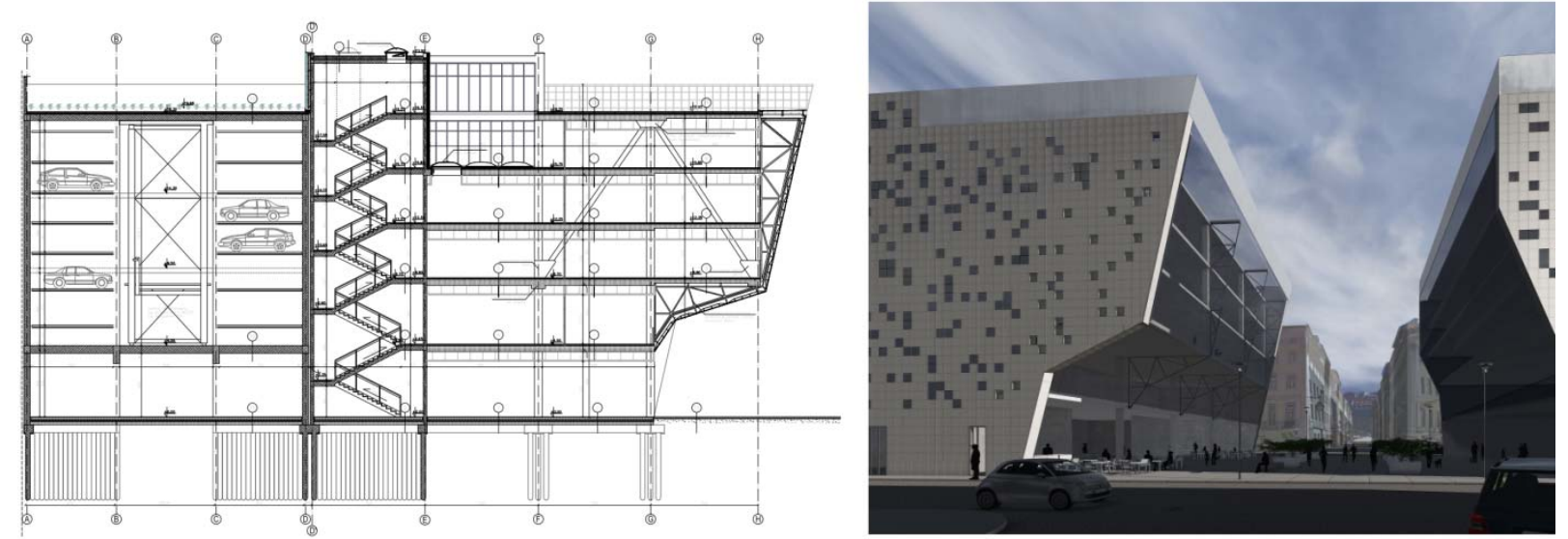

Fig.3. Vertical cross-section and visualization author's project of the building in Lisbon.

The foundations of the described object are made of reinforced concrete micro-piles. The decision to apply this kind of deep foundations was derived from unfavourable soil conditions such as flat area at only 6.5 meters and short proximity to the Tagus river. However, another significant factor of this choice is the past of the location - the Great Earthquake of Lisbon in 1755. 


\section{Consequences of an earthquake}

Movements and tremors of the surface of the Earth are happening all the time and are impossible to stop. Until they are minor, they have no influence on everyday activities neither on the systems used for construction. However many times engineers must take into consideration the parameters of seismic activity of particular areas.

Simply speaking, the mentioned movements are effects of sudden release of energy in the Earth's crust which create seismic waves. The produced seismic loads are one of the dynamic loads, that affect the construction. Sometimes they are the most influential sources of building's loads when it comes to section bearing capacity.

Tectonic plates that form the crust of the Earth are moving on a liquid layer called asthenosphere. When their edges dovetail and block the possibility of movement, stresses appear and, if they are exceeding the resistance of the rock to shearing force, cause cracks along so called fault line. The released energy turns into seismic waves which provoke displacements of the building's base. There are four types of seismic waves: material P-waves (base waves - cause compression of rocks), material S-waves (transversal - create transversal deformations without change of volume), surface Love waves and surface Rayleigh waves.

The loads caused by earthquakes that affect the construction are mainly the horizontal inertial forces. Due to the fact that buildings are designed for vertical static loads and are more resistant in this direction, the vertical forces are usually ignored in calculation. Values of horizontal inertial forces depend on the values of soil acceleration during the earthquake, mass of the building and type of structure. In an ideal situation, the building and its foundations would be perfectly stiff and then the maximal forces of acceleration of horizontal forces would be equal to the product of mass and soil acceleration. However, in reality buildings are always elastic to some extent.

To attest how destructive a tremor may be, the Great Lisbon earthquake from 1755 can be recalled. Its magnitude is estimated by scientists in the range 8.5-9.0 on the moment magnitude scale, while the strongest annotated earthquake in history happened in 1960 in southern Chile and had 9.5. During the 3.5 or 6 minute long tremor 5 meters wide fissures opened in the city centre and after 40 minutes a tsunami entering the Tagus river engulfed the downtown area. Apart from that, the remaining buildings were burned up by a fire that broke out and lasted five days. Not only the capital of Portugal was demolished but also its coast and islands (Paulay and Priestley, 1990; Wen et al., 2002).

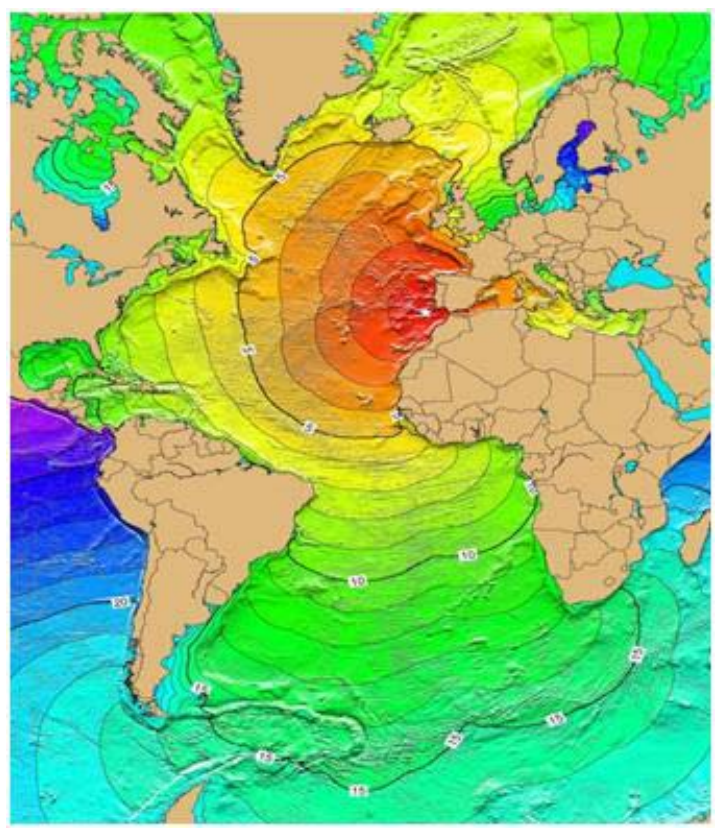

Fig.4. Great Lisbon earthquake in 1755. 
Moreover, the shocks were noticed throughout all Europe - in Finland, North Africa (20 meters high waves affected the coast) and the Caribbean. This earthquake gave birth to modern seismology and earthquake engineering as it was the first one studied scientifically due to its wide field of destruction.

\section{Numerical model of cablestayed cantilever structure}

A numerical model was made in Sofistik program. In the designed building the major difficulty is caused by the 10 meter cantilever, on which a glass facade was hung. This provokes substantial accretion of the forces occurring there. Implemented stay cables bear the forces of the cantilever, overcoming mostly the bending forces. The steel retaining blocks enable the transfer of all the loads from the hangers to the slab without the compulsion of excessive effort of columns. Otherwise the cross-section of the columns would increase significantly. Thankfully to their tension, the slabs are equalizing the tensile strengths. To avoid a possible puncture of the slab, inducted by the cutting force, an additional reinforcing mesh is provided. Due to the high durability of reinforced concrete to compressing forces, the columns are successfully bearing the forces steadily transferred from the slabs.

Due to the large distance between columns $(8.50 \mathrm{~m} \times 7.20 \mathrm{~m})$ as well as the desirable from architectural issues presence of cantilever, the post tension tendon slabs without adhesion were applied. Moreover, the Cobiax synthetic void formers were used to avoid unnecessary overloading of the structure this allowed a decrease in the weight of the slab up to $30 \%$. The method typical for bridges is used to prevent deformation of slabs and dangerous deflection on the cantilever - ties composed by steel tangles that transfer the loads to the slabs. Four floors were hung on the four pairs of stay cables of the length of 12.5 meters made of high endurance steel. The lines are anchored in the steel retaining blocks located in the columns from reinforced concrete and they are separated by expansion joints. In the bottom part the anchors are passive and in the top part they are active (responsible for proper tension of stay cables). Below the line of columns that contains the retaining blocks, the slabs are strengthened. Additionally, all the structure is stiffened by the core made of reinforced concrete, that is intended for vertical communication (Pawłowski, 2004).
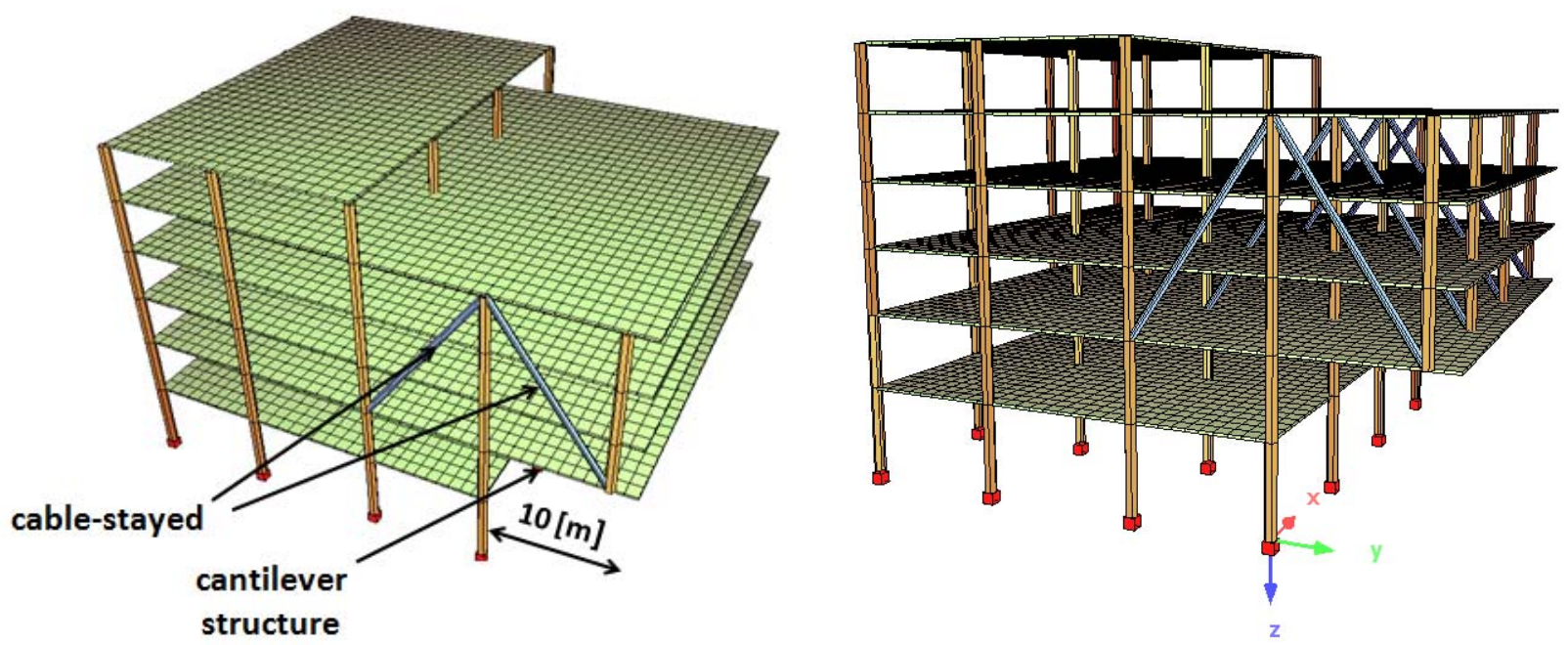


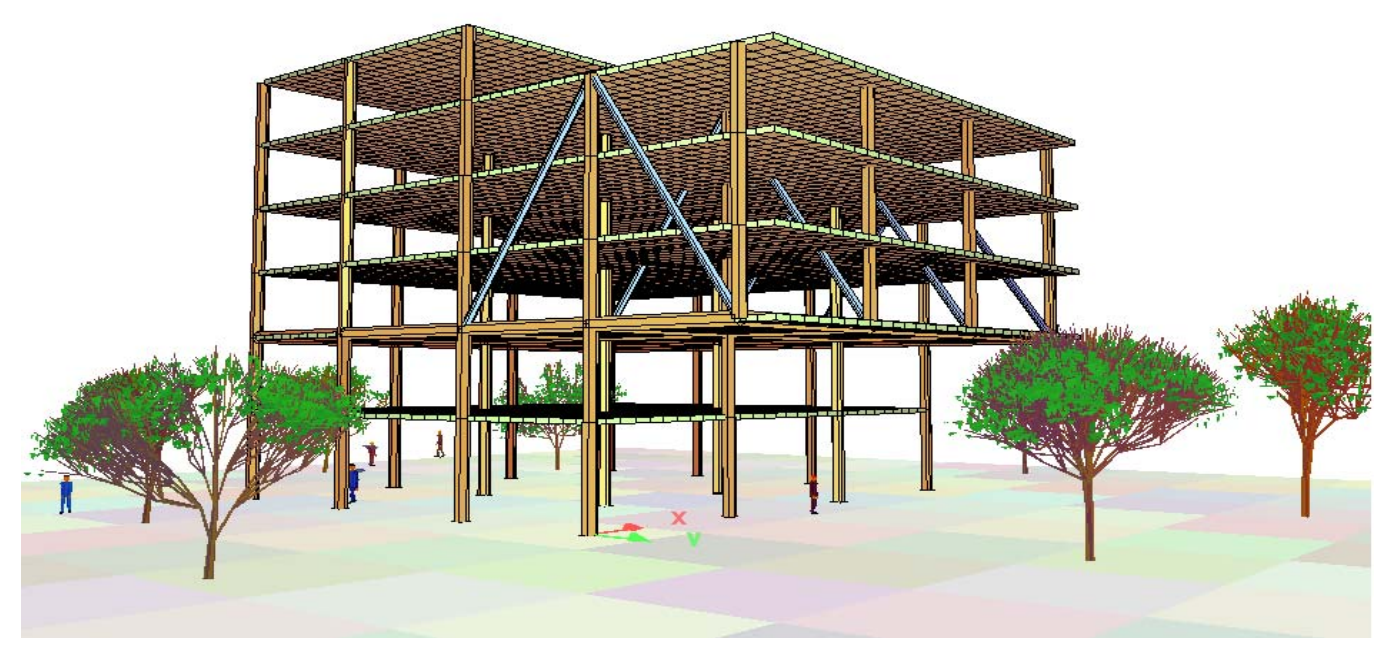

Fig.5. Numerical model of unique cantilever cablestayed structure.

\section{Modelling of an earthquake's dynamic impact on the structure}

One of the most frequently used methods of earthquake modelling is the method of spectrum of response, which applies averaged spectrum characteristics for particular seismic forces. When preparing conditions for analysis of complex and non-typical buildings we should take into account additional load of moments resulting from the circumvolution of a building in the horizontal plane and higher frequencies of a building's free vibration. For design purposes, seismic effect should be based on estimation of expected value resulting from hazard assessment.

The dynamic model of a building was assumed as a discrete model with masses in the form of ceiling shieldings. Horizontal elements, such as ceilings are treated as infinitely stiff surfaces and fragile. Due to the load caused by the earthquake, when designing a building, it should be presupposed that the strengthening elements are placed on the same level and are of the same height. The entire movement of a building is considered as in a springy condition and it is assumed that the movements of the strengthening elements are minimal.

The main formula to calculate vibrations of the system of numerous levels of freedom with a building loaded with earthquake forces is as follows

$$
M \ddot{q}+C \dot{q}+K q=p(t)
$$

where

$M$ - mass matrix (inertia)

$C$ - damping matrix

$K$ - stiffness matrix

$q-$ vector of generalized relocation

$p(t)$ - vector of effective seismic force

$$
p(t)=-\operatorname{Mr} \ddot{u}(t)
$$

where

$r$ - vector of the effect

Equation (5.1) is solved with the use of self transformation method, in which vector $q(t)$ is presented 


$$
q(t)=\sum_{i=1}^{n} a_{i} y_{i}(t)=A y
$$

where

$a_{i}-$ vector of the form of free non-attenuated vibrations

$y_{i}$ - normal coordinate

When dependencies from Eq.(5.3) are placed in Eq.(5.1), we obtain the following equation

$$
a_{i}^{T} M A \ddot{y}+a_{i}^{T} C A \dot{y}+a_{i}^{T} K A y=a_{i}^{T} p(t) .
$$

The condition of orthogonality gives us

$$
a_{i}^{T} M a_{j}=0 \quad \text { and } \quad a_{i}^{T} K a_{j}=0 .
$$

Due to the above mentioned relations, the orthogonal conditions result in the fact that only one element is different from zero in matrix product containing $M$ and $K$ matrices, if $i=j$. We can reduce the damping matrix $(C)$ in the same way. We first establish boundary conditions, which presuppose that the damping matrix is a linear combination of mass and stiffness matrices.

$$
C=u M+\chi K
$$

where:

$u, \chi$ - proportional ratio

Then we obtain

$$
a_{i}^{T} C a_{j}=0 \quad \text { for } \quad i \neq j .
$$

Alternatively, we may write it down as the following equation

$$
m_{i} \ddot{y}_{i}+c_{i} \dot{y}_{i}+k_{i} y_{i}=p_{i}(t) \quad \text { for } \quad i=1,2,3, \ldots, n
$$

where

$$
\begin{aligned}
& m_{i}=a_{i}^{T} M a_{i}, \quad c_{i}=a_{i}^{T} C a_{i}, \\
& k_{i}=a_{i}^{T} K a_{i}=\omega_{i}^{2} m_{i}, \quad p_{i}(t)=a_{i}^{T} p(t) .
\end{aligned}
$$

When we divide both sides of Eq.(5.8) by $m_{i}$ we end up with the following equation

$$
\ddot{y}_{i}+\frac{c_{i}}{m_{i}} \dot{y}_{i}+\frac{k_{i}}{m_{i}} y_{i}=\frac{1}{m_{i}} p_{i}(t) \text {. }
$$

Then, taking into account presupposition (5.9), we can write down Eq.(5.10) in the following way 


$$
\begin{aligned}
& \ddot{y}_{i}+2 \xi \omega_{i} \dot{y}_{i}+\omega_{i}^{2} y_{i}=\frac{1}{m_{i}} p(t), \\
& \xi=\frac{u}{2 \omega_{i}}+\frac{\chi \omega_{i}}{2}
\end{aligned}
$$

$\xi$ stands for the damping number. It is a number for the $i$-th form of vibrations. The differential Eq.(5.11) refers to mass and can be solved using Duhamel's integral

$$
\begin{aligned}
& y_{i}(t)=\frac{a_{i}^{T} B r}{a_{i}^{T} B a_{i}} \frac{1}{\omega_{i d}} \int_{o}^{t} \ddot{u}(r) e^{-i \xi \omega_{i}(t-r)} \sin \left[\omega_{i d}(t-r)\right] d r, \\
& \omega_{i d}=\omega_{i} \sqrt{1-\xi_{i}^{2}} .
\end{aligned}
$$

Thus, total reaction $q$ will be expressed by the formula

$$
q(t)=\sum_{i=1}^{n} a_{i} \eta_{i} \frac{1}{\omega_{i d}} \int_{o}^{t} \ddot{u}(r) e^{-i \xi \omega_{i}(t-r)} \sin \left[\omega_{i d}(t-r)\right] d r
$$

where

$$
\eta_{i}=\frac{a_{i}^{T} B r}{a_{i}^{T} B a_{i}} \quad \text { - tremor form role constant. }
$$

In accordance with the relations we may state that the share of the $i$-form of vibrations in the $j$ generalized coordinate $q_{i}$ is

$$
q_{i j}=A_{j i} \eta_{i} \frac{1}{\omega_{i d}} \int_{o}^{t} \ddot{u}(r) e^{-i \xi \omega_{i}(t-r)} \sin \left[\omega_{i d}(t-r)\right] d r
$$

where $A_{j i}$ is $j$-component of $i$-eigenvector. The maximum value of Duhamel's integral in the equation above is the value of response spectrum corresponding to $i$-natural frequency, thus we obtain the following equation

$$
\max q_{i j}=\left|A_{j i} \eta_{i} S_{d}\left(\xi_{i}, \omega_{i}\right)\right|=\left|A_{j i} \eta \frac{1}{\omega_{i}} S_{v}\left(\xi_{i} \cdot \omega_{i}\right)\right| .
$$

In order to estimate the total reaction of a building, one may not presuppose that maximum values of response of particular forms of vibrations occur at the same time. Thus, to determine the maximum response the SRSS and CQC methods are used. The SRSS method includes the following formula for $q_{\max }$

$$
\max q_{j}=\sqrt{\sum_{i-1}^{n}\left(\max q_{j i}\right)^{2}} .
$$


The formula is justified by the theory of random vibration. Calculations using this formula can lead to miscalculations in the case of irregular high buildings, in which the centre of mass is not consistent with the centre of the system's stiffness. Thus, in order to improve the SRSS method, the CQC method was introduced, which does not result in such miscalculations. This method is based on the following summation rule

$$
\max q_{j}=\sqrt{\sum_{i=1}^{n} \sum_{k=1}^{n}\left(\max q_{j i}\right) p_{i k}\left(\max q_{j k}\right)} .
$$

For a dynamic model of a building with a diagonal matrix of masses, we can estimate the maximum seismic force having effect on the $j$-th element of the building of $m_{j}$ mass at vibrations with $i$-th natural form. Then, using the SRSS and CQC methods, we determine the total seismic force putting load on the $j$-th element.

When designing a structure which is affected by seismic force according to Eurocode 8, we distinguish two methods of analysis. The first method (Fig.1a) - Response Spectra, is based on generation of response spectrum of the structure to an earthquake. In the other method (Fig.1b) - Accelerogram (BETA), we generate dynamic load in a form of a graph of dependency between acceleration and time for real readings obtained during the El Centro earthquake.

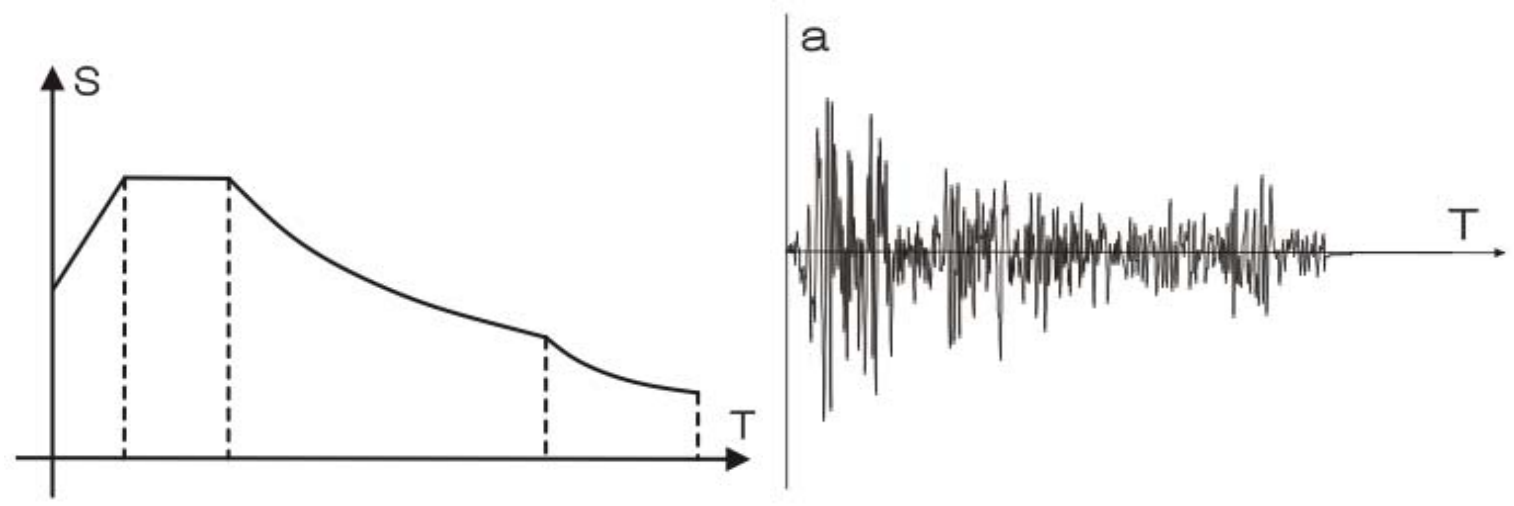

Fig.6. Two methods of seismic analysis - a) Spectra Response, b) Accelerogram.

The intensity of an earthquake can be best assessed based on full record of acceleration of the ground in a given place. Such a record can be used for calculating the response using numerical integration of equations of motion. Based on the results of construction relocation, we are able to count maximum internal forces for the construction loaded with an earthquake. Since structures are designed for future unknown earthquakes, for calculations we use a model accelerogram, presupposing that next earthquake will not be more destructive than the ones used as models. This is a deterministic approach. The inconveniences of the deterministic approach can be avoided by applying a description of an earthquake as a random phenomenon, in which the recorded accelerogram is a certain realization of a stochastic process and the oscillations of the building is analyzed using the theory of random vibration (Lapko and Jensen, 2006; Antecki and Wdowicki, 2007).

This approach is mainly used in scientific analysis, rather than in engineer's calculations. The most frequently used methods for engineer's calculations is the method of spectrum of response, which applies certain averaged spectrum characteristics for describing particular seismic forces. Below are numerical simulations of two different methods of seismic analysis performed with use of the SOFISITK software. 

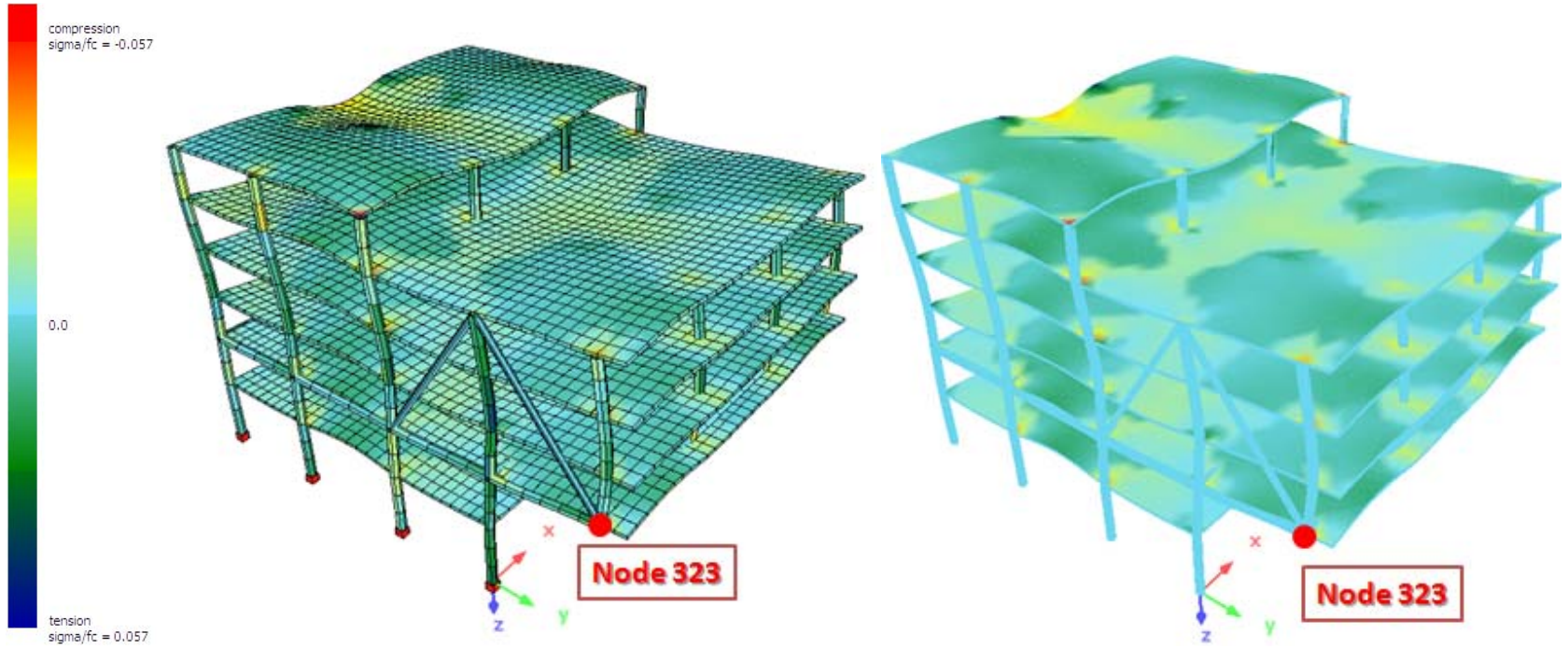

Fig.7. Numerical simulation of an earthquake - a) Spectra response, b) Accelerogram.

Below are the results of a comparison of moves of a multifunctional building in Lisbon for each of the two methods of generating the forces of an earthquake. For different values of prestressing force at the cable stays we obtained extreme values of stress in order to check the critical point of load and maximum bend. These were measured to verify the critical point for usability.

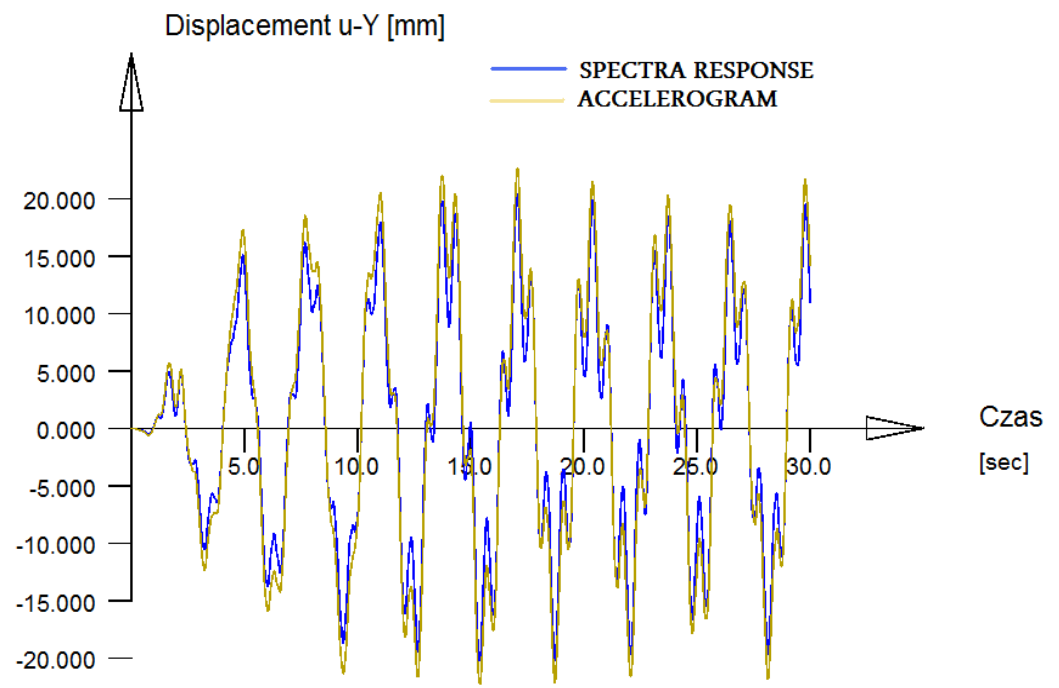

\begin{tabular}{|c|c|}
\hline \multicolumn{2}{|c|}{ Ultimate Limit State } \\
\hline Stress $\sigma$ & $385[\mathrm{MPa}]$ \\
\hline $\begin{array}{c}\text { Bending } \\
\text { moment } \mathrm{M}_{\max }\end{array}$ & $464[\mathrm{kNm}]$ \\
\hline
\end{tabular}

Fig.8. The results of calculations for the end of the cantilever structure (node 323) - prestressing force $N=1000 \mathrm{Kn}$. 


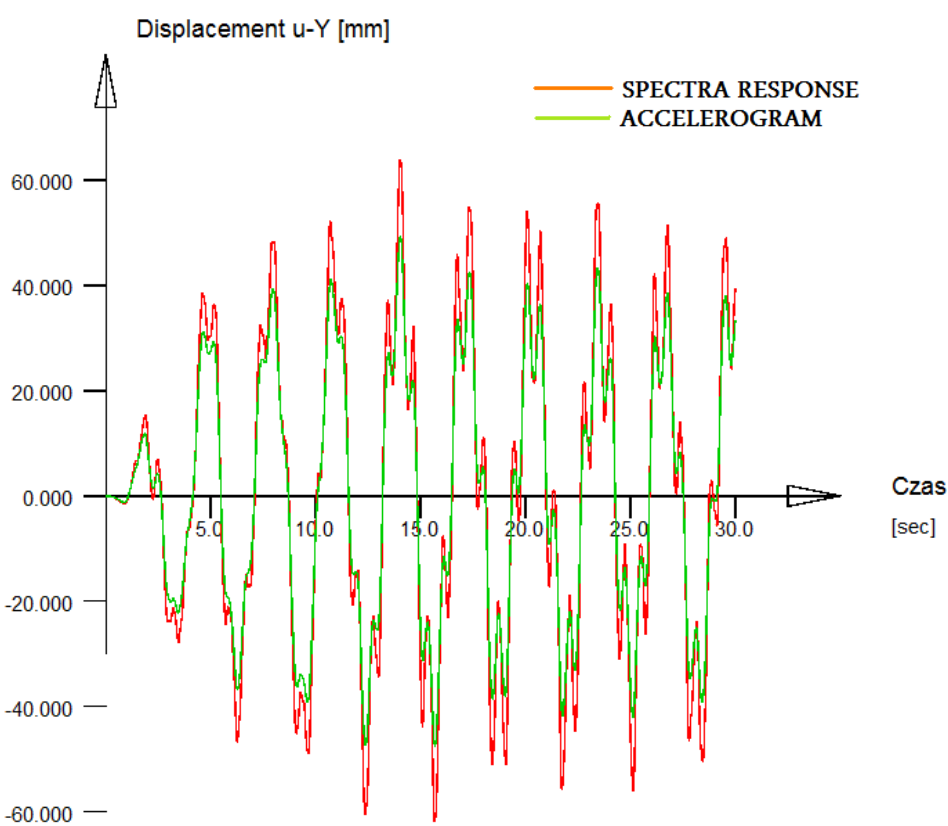

\begin{tabular}{|c|c|}
\hline \multicolumn{2}{|c|}{ Ultimate Limit State } \\
\hline Stress $\sigma$ & $652[\mathrm{MPa}]$ \\
\hline $\begin{array}{c}\text { Bending } \\
\text { moment } \mathrm{M}_{\max }\end{array}$ & $773[\mathrm{kNm}]$ \\
\hline
\end{tabular}

Fig.9. The results of calculations for the end of the cantilever structure (node 323) - prestressing force $N=2000 \mathrm{kN}$.

\section{Conclusions}

The aim of this article was to analyze the functioning of the applied bridge cable stays in buildings, depending on the introduced compressive force during earthquakes. The analysis indicated that cablestayed cantilever structures very effectively transfer seismic forces, but only if appropriate compressive force is introduced on the cable stays. If the compressive force is too high, the structure becomes stiff, which is extremely disadvantageous during earthquakes. Elements joined in a stiff manner accelerate each other, which can result in a construction disaster. If the compressive force is lower, the building is flexible (provided that the elements of the suspended structure are joined by a flexible joint with the rest of the building). Elements joined in an elastic way make particular parts of the structure move independently and prevent them from mutual acceleration. It is very easy to observe it on the graphs, where for the compressive force of $N=2000 \mathrm{kN}$, the maximum displacement of the cantilever is $60 \mathrm{~mm}$, while for the lowest compressive force of $N=1000 \mathrm{kN}$, the maximum displacement of the cantilever is $20 \mathrm{~mm}$. Based on the results it can be concluded that thanks to the application of cable-stayed cantilever structures in atypical constructions, we can prevent damage of buildings located in seismically active areas and guarantee safety to people using those buildings. Knowledge of the value of the compressive force needed for compression of cable stays as early as at the stage of designing, will allow an earlier elimination of errors and mistakes.

\section{Nomenclature}

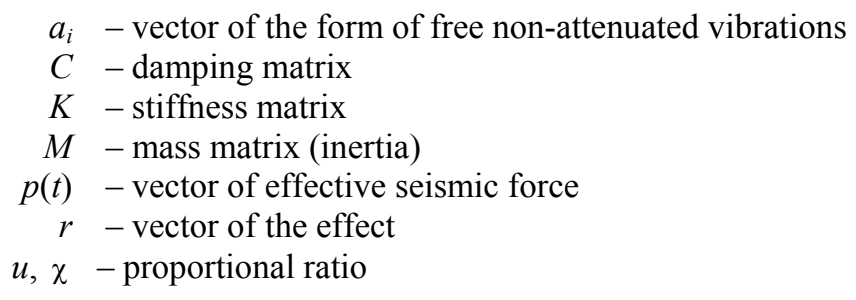


$q-$ vector of generalized relocation

$y_{i}$ - normal coordinate

\section{References}

Antecki P. and Wdowicki J. (2007): Building high-Di Wang Tower - Static, dynamic calculations and construction.Poznan University of Technology.

Balendra T. (1993): Vibration of Buildings to Wind and Earthquake Loads. - London: Springer - Verlag.

Englekirk R.T. (2003): Seismic Design of Reinforced and Precast Concrete Buildings. - Wiley.

Harries K.A. and Gong B. (2000): Behavior and design of reinforced concrete, steel and steel-concrete coupling beams. - Earthquake Spectra, vol.16, No.4, pp.775-800.

Kapela M. and Sieczkowski J. (2003): Designing high multi-storey buildings. - Warsaw University of Technology.

Li Q.S., Xiao Y.Q. and Wrong C.K. (2003): Field measurements of wind effects on the tallest building in Hong Kong. Structural Design of Tall and Special Buildings, vol.12, Wiley.

Łapko A. and Jensen B.Ch. (2006): The Designing Basis and Calculation Algorithms for the Reinforced Concrete Structures. - Warsaw: Arkady.

Paulay T. and Priestley M.J.N. (1990): Design of Reinforced Concrete and Masonary Buildings. - New York: Wiley.

Pawłowski A.Z. (2004): High buildings - the increasing role of concrete. - Construction, Technologies, Architecture, No.1(25), Publisher: Polish Cement Sp. z o.o..

Wen Z.P., Hu Y.X. and Chau K.T. (2002): Site effect on vulnerability of high-rise shear wall buildings under near and far field earthquakes. - Soil Dynamics and Earthquake Engineering, vol.22, Elsevier.

Wu J.R. and Li Q.S. (2003): Structural performance of multi-outrigger-braced tall buildings buildings. - The Structural Design of Tall and Special Buildings, vol.12, No.2, Wiley.

Received: April 20, 2015

Revised: July 16, 2015 